\title{
Accuracy of different handgrip values to identify mobility limitation in older adults
}

Maicon Luis Bicigo Delinocente ${ }^{1}$, Danilo Henrique Trevisan de Carvalho ${ }^{2}$, Roberta de Oliveira Máximo ${ }^{2}$, Marcos Hortes Nisihara Chagas ${ }^{1}$, Jair Licio Ferreira Santos ${ }^{3}$; Yeda Aparecida de Oliveira Duarte ${ }^{4}$; Andrew Steptoe ${ }^{5}$ Cesar de Oliveira ${ }^{5}$; Tiago da Silva Alexandre ${ }^{1,5^{*}}$

\section{Affiliations:}

${ }^{1}$ Post graduate program in Gerontology, Federal University of São Carlos, São Carlos, Brazil

${ }^{2}$ Post graduate program in Physiotherapy, Federal University of São Carlos, São Carlos, Brazil

${ }^{3}$ Department of Social Medicine, University of São Paulo, Ribeirão Preto, Brazil

${ }^{4}$ Department of Medical-surgical Nursing, University of São Paulo, São Paulo, Brazil

${ }^{5}$ Department of Epidemiology and Public Health, University College London, London, UK

\section{*Corresponding author:}

Department of Gerontology, Federal University of Sao Carlos, Rodovia Washington Luís, km 235, Sao Carlos, Sao Paulo 13565-905, E-mail: tiagoalexandre@ufscar.br 
Brief headline: The best grip strength cut-offs to identify mobility limitation in older adults are $<32 \mathrm{~kg}$ for men and $<21 \mathrm{~kg}$ for women. These values are a simple way to have an early diagnosis and develop interventions.

\section{Introduction}

Grip strength is one of the key components in the evaluation of frailty and sarcopenia and is strongly associated with diverse negative outcomes in older adults. ${ }^{1,2}$ Among such outcomes, the Foundation for the National Institutes of Health Sarcopenia Project reports that a mobility limitation is commonly the first physical functioning impairment that predisposes older adults to functional disability, falls, hospitalizations, institutionalization and premature death. ${ }^{2,3,4,5}$ 
Thus, it is important to have accurate assessment tools that are easy to administer and well tolerated by older adults to enable an early diagnosis of mobility limitation and the development of interventions that preserve functional capacity while allowing social interactions and reducing health care costs. However, although the relationship between muscle strength and physical functioning is well defined, little is known regarding the cutoffs of muscle strength that can assist in identifying limited mobility later in life. .,6,7,8,9 $^{5}$

The European Working Group on Sarcopenia in Older People (EWGSOP, 2018) recommends concentrating the diagnosis of sarcopenia on low muscle strength as its fundamental characteristic, suggesting cutoffs of $<27 \mathrm{~kg}$ for men and $<16 \mathrm{~kg}$ for women. Researchers have also suggested an association between low muscle strength and reductions in both muscle mass and quality and that a poor physical performance attributed to the mobility limitation is an indicator of the severity of sarcopenia. ${ }^{1,2}$

Lauretani and collaborators (2003) were the first researchers to present a cutoff for grip strength as a predictor of mobility limitation $(<30 \mathrm{~kg}$ for men and $<20 \mathrm{~kg}$ for women). Alley and collaborators (2014) proposed $<26 \mathrm{~kg}$ for men and $<16 \mathrm{~kg}$ for women; not as a predictor of mobility limitation, but as a better indicator of loss of muscle strength. In 2015, Vasconcelos and collaborators suggested new cutoffs: $<25.8 \mathrm{~kg}$ for men and $<17.4 \mathrm{~kg}$ for women. ${ }^{11,12,13}$ 
Cawthon and collaborators (2019) describe grip strength as the best discriminator for limited mobility, highlighting the need for further studies involving the development of a risk model capable of predicting this outcome considering age, sex and comorbidities, since existing cutoffs do not predict impaired mobility and do not present good accuracy analyses. Therefore, the aim of the present study was to establish a cutoff for grip strength that enables identifying mobility limitation in older adults and compare it to the accuracy properties attributed to the cutoffs of $<26,<27$ and $<30 \mathrm{~kg}$ for men and $<16,<17$ and $<20 \mathrm{~kg}$ for women found in the literature.

\section{Methods}

\section{Study population}

The data were extracted from the Health, Wellbeing and Aging Study (SABE), which is a longitudinal study with a probabilistic, representative sample of individuals aged 60 years or older residing in urban areas of the city of São Paulo, Brazil, and the English Longitudinal Study of Ageing (ELSA), which is a longitudinal study with a representative sample of adults aged 50 years or older residing in England. Detailed descriptions of both studies can be found elsewhere. ${ }^{14,15,16,17,18}$ 
We used data from the third wave of the SABE study (2010) involving 1,344 individuals and the sixth wave of the ELSA (2012) involving 7,107 individuals. All participants were aged 60 years or older. Three hundred SABE participants were excluded due to missing data on mobility, grip strength or other covariables, resulting in a final sample of 1,044 individuals. A total of 2,368 individuals were excluded from the ELSA study for the same reasons, resulting in a final sample of 4,739 individuals. Thus, the total analytical sample in the present study comprised of 5,783 individuals.

All participants signed a statement of informed consent. The SABE study received approval from the Human Research Ethics Committee of the School of Public Health of the University of São Paulo. The ELSA study received approval from the National Research Ethics Service - London Multicentre Research Ethics Committee.

\section{Mobility assessment}

In both studies, mobility was assessed using the walk test of the Short Physical Performance Battery Assessing Lower Extremity Function and mobility limitation was defined as a gait speed $<0.8 \mathrm{~m} / \mathrm{s}^{11,12,19}$

\section{Muscle strength assessment}


Grip strength was determined using a manual dynamometer (Takei Kiki Kogyio TK 1201 in the SABE study and Smedley in the ELSA study). During the trials, the participant remained seated with the elbow supported on the table and the forearm and hand turned upward. The participant was then instructed to squeeze the dynamometer as strongly as possible. Two trials were performed with the dominant upper limb and a one-minute rest interval between trials. The largest of the two values was considered in the analysis. ${ }^{20,21}$

\section{Covariables}

Socio-demographic, lifestyle and health characteristics associated with mobility limitation were included as covariates.

Socio-demographic characteristics: age (in years), schooling years (> 13 years; 12-13 years; 0-11 years), marital status (with or without a conjugal life) and income (categorized in quintiles). ${ }^{22}$

Behavioral characteristics: In the SABE study, physical activity level was determined using the Brazilian version of the International Physical Activity Questionnaire, with individuals who performed less than 150 minutes of moderate physical activity and/or less than 75 minutes of vigorous physical activity per week considered insufficiently active. ${ }^{23,24}$ In the ELSA study, physical activity level was determined using three questions 
taken from a validated instrument used in the Health Survey for England, for which higher scores indicate a greater frequency and intensity of activities. The participants informed the frequency (once a week, more than once a week, one to three times a month, hardly ever or never) of performing vigorous (running, swimming, cycling, tennis, aerobics, weight lifting), moderate (gardening, washing the car, walking at a moderate pace, dancing, stretching) and light (vacuuming the home, washing clothes, doing home repairs) exercises. Physical activity was also categorized into two groups: a sedentary lifestyle (no weekly activity) or active lifestyle (light, moderate or vigorous activity at least once a week). ${ }^{25}$ Regarding smoking sttaus, the individuals were classified as smokers, ex-smokers or non-smokers. Alcohol intake was classified as never or rarely (up to once a week), often (two to six times a week) or daily in both studies. ${ }^{22}$

Health conditions: self-reported doctor diagnosed arterial hypertension, diabetes, stroke, heart disease, lung disease, joint disease, osteoporosis, cancer; body mass index (BMI) categorized according to the classification proposed by the World Health Organization as undernourished $(<$ $\left.18.5 \mathrm{~kg} / \mathrm{m}^{2}\right)$, ideal range $\left(\geq 18.5\right.$ and $\left.<25 \mathrm{~kg} / \mathrm{m}^{2}\right)$, overweight $\left(\geq 25\right.$ and $\left.<30 \mathrm{~kg} / \mathrm{m}^{2}\right)$ or obese $\left(\geq 30 \mathrm{~kg} / \mathrm{m}^{2}\right)$; the occurrence of falls in the previous 12 months; and polypharmacy (use of more than five medications). ${ }^{21}$ Depressive symptoms were evaluated using the Geriatric Depression Scale in the SABE study ( $\geq 5$ points considered risk of depression) and the Center for Epidemiologic Studies Depression Scale in the ELSA study ( $\geq 4$ points considered risk of depression). ${ }^{26,27}$ 
Functioning: number of self-reported difficulties performing basic activities of daily living (using the modified Katz Index) and instrumental activities of daily living (using the modified version of the Lawton Scale). ${ }^{28,29}$

\section{Statistical analysis}

The characteristics of the sample were expressed as means, standard deviations and proportions. Differences between (1) included participants and excluded participants (due to missing data) as well as (2) sex and mobility status were analyzed using the chi-squared ( $\mathrm{x}^{2}$ ) test, ANOVA and Tukey's post-hoc test. A p-value $<0.05$ was considered indicative of statistical significance.

Sensitivity, specificity, log-likelihood positive (LR+), negative (LR-) and Youden Index values were calculated to determine the accuracy of grip strength in identifying mobility limitation. Once the best cutoffs were determined, the probability of exhibiting impaired mobility was calculated using a logistic regression model adjusted for the covariables using the stepwise forward method $(\mathrm{p}<0.20)$ in the univariate analyses. The area under the receiver operating characteristic (ROC) curves of the adjusted models was analyzed and a bootstrap model was created for the confirmation of the results. Other cutoffs in the literature $(<26,<27$ and $<30 \mathrm{~kg}$ for men; $<16,<17$ and $<20 \mathrm{~kg}$ for women) were submitted to the same accuracy analyses for the purposes of comparison to the cutoffs proposed in the present study ( $<32 \mathrm{~kg}$ for men and $<21 \mathrm{~kg}$ for women). The Stata $14 \circledast$ statistical package was used for all analyses. 


\section{Results}

Table 1 displays the socio-demographic and behavioral characteristics of the sample stratified by sex and mobility status. Table 2 displays the health conditions, anthropometric data and functioning of the sample. Impaired mobility was more prevalent among the women (37.3\%) than the men $(28.9 \%)$. In both sexes, individuals with impaired mobility were older, had no conjugal life, were in the intermediate income quintile and had less schooling. They also never or rarely consumed alcohol and had more health problems, lower mean grip strength, a higher mean BMI and greater number of difficulties performing basic and instrumental activities of daily living $(\mathrm{p}<0.05)$.

The participants excluded due to missing data were younger, had a conjugal life, fewer schooling years and were in the intermediate income quintile. Most were ex-smokers, consumed alcohol frequently, were overweight and had fewer health problems. These individuals had greater mean grip strength, were slower, reported more difficulties to perform activities of daily living, fell less often and had fewer depressive symptoms than the individuals included in the sample $(\mathrm{p}<0.05)$. 
The balance between the sensitivity, specificity, LR+, LR- and Youden Index values indicated that the best cutoffs were $<32 \mathrm{~kg}$ for men $(49.1 \%$ sensitivity, 79.8\% specificity, LR+ of 2.43, LR- of 0.64 and Youden Index of 28.9$)$ and $<21 \mathrm{~kg}$ for women $(58.6 \%$ sensitivity, $72.9 \%$ specificity, LR+ of 2.16, LR- of 0.57 and Youden Index of 31.5).

Table 3 shows the diagnostic accuracy properties of the cutoffs proposed herein as well as those described in the literature and applied to the present sample. Odds ratios (OR) and their respective 95\% confidence intervals (CI) were calculated to estimate the odds of a mobility limitation among men and women based on the cutoffs determined in the present study and those reported in the literature. The results of the logistic regression model adjusted for the covariates are presented in Table 4 and were confirmed by the bootstrap model. Finally, ROC curves were plotted from the adjusted model as well as the graphs of the relation between sensitivity and specificity and the probability of the cutoffs proposed in the present investigation i.e. $<32 \mathrm{~kg}$ for men and $<21 \mathrm{~kg}$ for women (Figure 1).

\section{Discussion}

The present findings suggest that a grip strength $<32 \mathrm{~kg}$ for men and $<21 \mathrm{~kg}$ for women are indicators of a greater probability of a mobility limitation among older adults. The cutoff of $<32 \mathrm{~kg}$ for men had $49.1 \%$ sensitivity, $79.8 \%$ specificity, LR+ of 2.43, LR- of 0.64 and a Youden Index of 28.9 , whereas the cutoff of $<21 \mathrm{~kg}$ for women had $58.6 \%$ sensitivity, $72.9 \%$ specificity, LR+ of 2.16, LR- of 0.57 and a Youden Index of 31.5 . In the 
fully adjusted model using these cutoff points, the area under the curve (AUC) was 0.82 for men and 0.83 for women, with an OR of 1.88 [95\%CI: $1.50-2.37]$ for men and 1.89 [95\%CI: $1.57-2.27]$ for women.

Although different from the cutoffs adopted in the literature, our results are very close to the cutoffs proposed by Lauretani and collaborators (2003): $<30 \mathrm{~kg}$ for men and $<20 \mathrm{~kg}$ for women. This was the first epidemiological study to propose a single cutoff point for grip strength as a predictor of the mobility limitation for each sex. However, the authors did not present sensitivity, specificity or other important components of the accuracy analysis, which impedes a more precise comparison of our results and those reported in the study cited. ${ }^{12}$

The same authors tested indicators of sarcopenia thought to be associated with impaired mobility and concluded that there is a strong relation between grip strength and lower limb muscle strength, considering it to be the best clinical marker for limited mobility. Sarcopenia was considered when grip strength was more than two standard deviations below the mean of the young population. The authors calculated the percentage of individuals who exhibited a mobility limitation and compared the values in models adjusted for age, which resulted in an AUC or 0.79 and an OR of 2.7 [95\%CI: $1.4-5.0$ ] for men as well as an AUC of 0.90 and an OR of 6.9 [95\%CI: 2.1 - 23.3] for women. ${ }^{12}$

In 2014, Alley and collaborators sought to identify cutoffs that determined clinically relevant weakness associated with impaired mobility. The authors analyzed data from multiple studies linked to the Foundation for the National Institutes of Health Biomarkers Consortium Sarcopenia 
Project involving a sample of 9,897 men and 10,950 women, dividing the grip strength data into categories (normal, intermediate and weak) and cross-referencing with data obtained for walking speed. The authors found that grip strength $<26 \mathrm{~kg}$ for men and $<16 \mathrm{~kg}$ for women best indicated a greater probability of clinically important impaired muscle strength. ${ }^{8}$

Like Lauretani and collaborators (2003), Alley and collaborators (2014) also failed to present measures of sensitivity, specificity, LR+ and LR-. The authors only showed that men and women below the suggested cutoffs were respectively seven-fold and four-fold more likely to have clinically evident muscle weakness. When applied to the present sample, the results were not satisfactory and our cutoffs performed better in terms of the accuracy properties. ${ }^{8,12}$

Vasconcelos and collaborators (2015) analyzed the accuracy of grip strength for mobility limitation based on data from 1,374 older Brazilian adults who participated in the FIBRA study. The authors calculated sensitivity, specificity, positive predictive values and negative predictive values, proposing cutoffs of $<25.8 \mathrm{~kg}$ for men and $<17.4 \mathrm{~kg}$ for women. ${ }^{13}$ However, when applied to the present sample, the results were unsatisfactory and similar to those found when using the cutoffs proposed by Alley and collaborators (2014).

In 2018, the EWGSOP recommended low muscle strength as a fundamental characteristic for the diagnosis of sarcopenia and a poor physical performance as an indicator of the severity of this condition. The group suggests that low muscle strength is considered when grip strength is < 
$27 \mathrm{~kg}$ for men and $<16 \mathrm{~kg}$ for women. For mobility limitation, the group suggests that a poor physical performance is considered when walking speed is $<0.8 \mathrm{~m} / \mathrm{s}$. However, neither the grip strength cutoff of $<16 \mathrm{~kg}$ for women, previously proposed by Alley and collaborators $(2014)$, nor $<$ $27 \mathrm{~kg}$ for men presented good accuracy when applied to the present sample. ${ }^{2,10}$

None of the cutoffs for grip strength described in the literature or those proposed in the present study have high sensitivity. However, mobility is a complex phenomenon for which neuromuscular strength is not the only component. Thus, it is not possible to demand better results for diagnostic properties, as other variables exert an influence on this process. Hence, we believe that our sensitivity values, although not particularly high, are very satisfactory..$^{31,32}$

The same may be true for the Youden Index, which did not indicate a good performance of grip strength as a predictor of mobility limitation in the present study. Nonetheless, this index did not render the test useless and favored our cutoffs. The values of this index range from 0 to 1 , for which 0 indicates the same proportion of positive results for groups with and without a disease (useless test) and 1 indicates the absence of false positive and false negatives (perfect test). ${ }^{33}$ 
On the other hand, even though our cutoffs did not show a good sensitivity, the specificity was satisfactory. Good specificity guarantees the test with a rare erroneous classification (false positives). In this sense, the cutoffs presented by our study, compared to those proposed in the literature, would not classify older adults with preserved mobility as individuals with mobility limitations.

The results of the AUC analysis confirm the accuracy of our cutoffs. The fully adjusted model showed an AUC of 0.82 for men and 0.83 for women. An AUC $\geq 0.9$ indicates high precision, 0.7 to 0.9 indicates moderate precision and 0.5 to 0.7 indicates low precision. Thus, a test can be considered adequate when the AUC is $\geq 0.75 .^{34}$

Moreover, working with higher cutoffs seems more advantageous, as they enable an early diagnosis, development of interventions that can preserve functional capacity, ensure social interactions and contribute to reducing health care costs. All these factors lend support to the present findings.

The strengths and limitations of our study should be acknowledged. The following are the main strong points: the use of data from large and representative samples; the use of mobility limitation probability models adjusted for important variables associated with the outcome which allowed the size of the associations of the cutoffs tested to be analyzed independently of confounding variables; and the comparison of our cutoffs to those described in previous studies, thereby enabling the choice of the best values. The main limitation of the study was the fact that the exclusion of individuals for whom no data was available on grip strength, walking speed or other covariables could have biased the results to some degree. 


\section{Conclusion}

A grip strength $<32 \mathrm{~kg}$ for men and $<21 \mathrm{~kg}$ for women showed the best probability to identify mobility limitation among older adults in Brazil and England, after comparing their accuracy properties to the cutoffs described in the literature.

\section{Acknowledgments}

The authors are grateful to all the staff who worked on the SABE and ELSA studies and all participants in the two studies.

\section{Conflict of interest}

The authors declare that they have no conflict of interest.

\section{Funding}

The SABE study is funded by the Foundation for Research Support of the State of São Paulo (FAPESP), grant number 2009/53778-3. ELSA is funded by the National Institute on Aging USA (grant number 5R01AG017644-16) and a consortium of United Kingdom government departments coordinated by the Economic and Social Research Council (ESRC). The Brazilian National Council for Scientific and Technological Development 
(CNPq) funds Tiago da Silva Alexandre (grant number 303981/2017-2). This study was financed in part by the CNPq through the Institutional

Program of Scientific Initiation Scholarships - PIBIC (grant number 113586/2018-3).

\section{References}

1. DODDS, R. M. et al. Grip strength across the life course: normative data from twelve British studies. PloS one, v. 9, n. 12, p. e113637, 2014.

2. CRUZ-JENTOFT, A. J. et al. Sarcopenia: revised European consensus on definition and diagnosis. Age and ageing, 2018.

3. ALEXANDRE, T. S. Prevalence and associated factors of sarcopenia among elderly in Brazil: Findings from the SABE study. The Journal of Nutrition, Health \& Aging, v. 18, n. 3, p. 284-290, 2014.

4. CAWTHON, P. M. et al. Cutpoints for low appendicular lean mass that identify older adults with clinically significant weakness. The Journals of Gerontology Series A: Biological Sciences and Medical Sciences, v. 69, n. 5, p. 567-575, 2014.

5. KIM, T. N.; CHOI, K. M. Sarcopenia: definition, epidemiology, and pathophysiology. Journal of Bone Metabolism, v. 20, n. 1, p. 1-10, 2013.

6. CAWTHON, P. M. et al. Establishing the Link Between Lean Mass and Grip Strength Cut-points With Mobility Disability and Other Health Outcomes: Proceedings of the Sarcopenia Definition and Outcomes Consortium Conference. The Journals of Gerontology: Series A, 2019.

7. MCLEAN, R. R. et al. Criteria for clinically relevant weakness and low lean mass and their longitudinal association with incident mobility impairment and mortality: the foundation for the National Institutes of Health (FNIH) sarcopenia project. The Journals of Gerontology Series A: Biological Sciences and Medical Sciences, v. 69, n. 5, p. 576-583, 2014. 
8. STUDENSKI, S. A. et al. The FNIH sarcopenia project: rationale, study description, conference recommendations, and final estimates. The Journals of Gerontology Series A: Biological Sciences and Medical Sciences, v. 69, n. 5, p.547-558, 2014.

9. MANINI, T. M. Mobility decline in old age: a time to intervene. Exercise and sport sciences reviews, v. 41, n. 1, p. $2,2013$.

10. ALLEY, D. E. et al. Grip strength cutpoints for the identification of clinically relevant weakness. The Journals of Gerontology Series A: Biological Sciences and Medical Sciences, v. 69, n. 5, p. 559-566, 2014.

11. CRUZ-JENTOFT, A. J.et al. Sarcopenia: European consensus on definition and diagnosis: Report of the European Working Group on Sarcopenia in Older People. Age and Ageing, v. 39, n. 4, p. 412-423, 2010.

12. LAURETANI, F. et al. Age-associated changes in skeletal muscles and their effect on mobility: an operational diagnosis of sarcopenia. Journal of Applied Physiology, v. 95, n. 5, p. 1851-1860, 2003.

13. VASCONCELOS, K. S. S. et al. Handgrip strength cut-off points to identify mobility limitation in community-dwelling older people and associated factors. The journal of nutrition, health \& aging, v. 20, n. 3, p. 306-315, 2016.

14. PALlONI, A.; PELÁEZ, M. Histórico e natureza do estudo. In: LEBRÃO, M. L. (Org.); DUARTE, Y. A. O. (Org.) SABE - Saúde, Bemestar e Envelhecimento - O projeto SABE no Município de São Paulo: uma abordagem inicial. Brasília: Distrito Federal, cap.1, p. 15, 2003.

15. SILVA, N. N. Aspectos Metodológicos: Processo de amostragem. In: LEBRÃO, M.L. (Org.); DUARTE, Y.A.O. (Org.). SABE- Saúde, Bemestar e Envelhecimento - O projeto SABE no Município de São Paulo: uma abordagem inicial. Brasília: Distrito Federal, cap. 3, p. 47, 2003.

16. LEBRÃO, M. L.; DUARTE, Y. A. O. D. Desafios de um estudo longitudinal: o Projeto SABE. Saúde Coletiva, v. 5, n. 24, p. 166-167, 2008. 
17. MARMOT, M. et. al. English Longitudinal Study of Ageing: Wave 0 (1998, 1999 and 2001) and Waves 1-4 (2002-2009) [computer file]. 15th

Edition. UK. Archive [distributor]; Colchester, Essex: 2011. SN: 5050

18. STEPTOE, A. et al. Cohort Profile: The English Longitudinal Study of Ageing. International Journal of Epidemiology, v. 42, n. 6, p. 16401648, 1 dez. 2013

19. GURALNIK, J. M. Assessment of physical performance and disability in older persons. Muscle \& Nerve, v. 20, n. S5, p. 14 - $16,1997$.

20. AL SNIH, S. et al. Handgrip strength and incident ADL disability in elderly Mexican Americans over a seven-year period. Aging Clinical and Experimental Research, v. 16, n. 6, p. 481-486, 2004.

21. BOHANNON, R. W.; MAGASI, S. Identification of dynapenia in older adults through the use of grip strength tscores. Muscle $\&$ Nerve, v. 51, n. 1, p. 102-105, 2015.

22. ALEXANDRE, T. S. et al. The combination of dynapenia and abdominal obesity as a risk factor for worse trajectories of IADL disability among older adults. Clinical Nutrition, v. 37, n. 6, p. 2045-2053, 2018.

23. GUEDES, D. P.; LOPES, C. C.; GUEDES, J. E. R. P. Reprodutibilidade e validade do Questionário Internacional de Atividade Física em adolescentes. Revista Brasileira Medicina do Esporte v. 11, n. 2, p. 151-157, 2005.

24. VON BONSDORFF et al. Mobility limitations and cognitive deficits as predictors of institutionalization among community-dwelling older people. Gerontology, v. 52, n. 6, p. 359-365, 2006.

25. LEEDS UK. Joint Health Surveys Unit, National Centre for Social Research and University Collegeand Public Health. Health Surv Engl. 2008. 
26. ALMEIDA, O. P.; ALMEIDA, S. A. Short versions of the geriatric depression scale: a study of their validity for the diagnosis of a major depressive episode according to ICD10 and DSMIV. International Journal of Geriatric Psychiatry, v. 14, n. 10, p. 858-865, 1999.

27. YESAVAGE, J. A.; SHEIKH, J. I. 9/Geriatric depression scale (GDS) recent evidence and development of a shorter version. Clinical gerontologist, v. 5, n. 1-2, p. 165-173, 1986.

28. KATZ, S. et al. Studies of illness in the aged: the index of ADL: a standardized measure of biological and psychosocial function. Journal of The American Medical Association, v. 185, n. 12, p. 914-919, 1963.

29. LAWTON, M. P.; BRODY, E. M. Assessment of Older People: Self-Maintaining and Instrumental Activities of Daily Living. Nursing Research, v. 19, n. 3, p. 278, 1970.

30. MCGEE, S. Evidence-based physical diagnosis e-book. Elsevier Health Sciences, 2012.

31. CESAR C. C. et. al. Capacidade funcional de idosos: análise das questões de mobilidade, atividades básicas e instrumentais da vida diária via teoria de resposta ao item. Caderno Saúde Pública, 2015.

32. SILVA N. A.; PEDRAZA D. F.; MENEZES T. N. Desempenho funcional e sua associação com variáveis antropométricas e de composição corporal em idosos. Ciência Saúde Coletiva. 2015

33. YOUDEN, W. J. Index for rating diagnostic tests. Cancer, v. 3, n. 1, p. 32-35, 1950.

34. BARBOSA-SILVA, T. G. et al. Enhancing SARC-F: Improving sarcopenia screening in the clinical practice. Journal of the American Medical Directors Association, v. 17, n. 12, p. 1136-1141, 2016. 
Table 1. Socio-demographic and behavioral characteristics of 5,783 older adults from the SABE and ELSA studies stratified by sex and mobility status

\begin{tabular}{|c|c|c|c|c|}
\hline & \multicolumn{2}{|c|}{$\operatorname{Men}(n=2,510) 43.4 \%$} & \multicolumn{2}{|c|}{ Women $(n=3,273) 56.6 \%$} \\
\hline & $\begin{array}{c}\text { Normal } \\
\text { mobility } \\
(\mathrm{n}=\mathbf{1 , 7 8 5}) \mathbf{7 1 . 1 \%}\end{array}$ & $\begin{array}{c}\text { Mobility } \\
\text { limitation } \\
(n=725) 28.9 \%\end{array}$ & $\begin{array}{c}\text { Normal } \\
\text { mobility } \\
(\mathrm{n}=\mathbf{2 , 0 5 2 ) 6 2 . 7 \%}\end{array}$ & $\begin{array}{c}\text { Mobility } \\
\text { limitation } \\
(\mathbf{n}=\mathbf{1 , 2 2 1}) 37.3 \%\end{array}$ \\
\hline \multicolumn{5}{|l|}{ Socio-demographic characteristics } \\
\hline Age, years (SD) & $68.8(6.5)^{* \S}$ & $74.2(8.4)^{* \S}$ & $68.2(6.2)^{* \S}$ & $73.9(8.1)^{* \S}$ \\
\hline $60-69(\%)$ & $60.1 * \S$ & $33.1 *$ & $63.6 * \S$ & $33.0 *$ \\
\hline $70-79(\%)$ & $32.3 * \S$ & $40.0 *$ & $31.0 * \S$ & $40.6^{*}$ \\
\hline 80 or more $(\%)$ & $7.6^{*} \S$ & $26.9 *$ & $5.4 * \S$ & $26.4^{*}$ \\
\hline Marital status (with conjugal life) (\%) & $81.5^{*} \S$ & $69.0 * \S$ & $62.6^{*} \S$ & $44.5^{*} \S$ \\
\hline Highest income quintile $(\%)$ & $54.5^{* \S}$ & $27.6^{* \S}$ & $47.0 * \S$ & $22.4 * \S$ \\
\hline Intermediate income quintile (\%) & $36.2 * \S$ & $48.8 * \S$ & $38.2 * \S$ & $48.4 * \S$ \\
\hline Lowest income quintile (\%) & $7.1 * \S$ & $21.8 * \S$ & $11.1 * \S$ & $24.4 * \S$ \\
\hline Income not declared (\%) & $2.2 * \S$ & $1.8 * \S$ & $3.7 * \S$ & $4.8^{*} \S$ \\
\hline$>13$ years of schooling $(\%)$ & $42.7 * \S$ & $19.7 * \S$ & $25.4 * \S$ & $13.2 * \S$ \\
\hline $12-13$ years of schooling $(\%)$ & $21.7 * \S$ & $17.9 * \S$ & $26.9 * \S$ & $17.2 * \S$ \\
\hline $0-11$ years of schooling $(\%)$ & $35.6 * \S$ & $62.4 * \S$ & $47.7 * \S$ & $69.6^{* \S}$ \\
\hline \multicolumn{5}{|l|}{ Behavioral characteristics } \\
\hline Level of physical activity (active) (\%) & $91.3 *$ & $74.5^{*} \S$ & $92.7^{*}$ & $78.6^{*} \S$ \\
\hline \multicolumn{5}{|l|}{ Weekly alcohol intake (\%) } \\
\hline Never or rarely & $17.4 * \S$ & $37.9 *$ & $31.7 * \S$ & $59.1 *$ \\
\hline Often & $35.3 * \S$ & $33.5^{*}$ & $40.7 * \S$ & $26.9 *$ \\
\hline Daily & $47.3 * \S$ & $28.6^{*}$ & $27.6^{*} \S$ & $14.0^{*}$ \\
\hline \multicolumn{5}{|l|}{ Smoking (\%) } \\
\hline Non-smoker & $30.7 * \S$ & $21.8 * \S$ & $47.8^{\S}$ & $47.0 \S$ \\
\hline Ex-smoker & $60.6 * \S$ & $66.2 * \S$ & $43.6^{\S}$ & $42.4 \S$ \\
\hline Smoker & $8.7 * \S$ & $12.0 * \S$ & $8.6^{\S}$ & $10.6^{\S}$ \\
\hline
\end{tabular}


Note: Data expressed as proportion, mean, and standard deviation. * Difference per mobility status in same sex (p $<0.05)$. § Difference between sexes within same mobility status $(p<0.05)$ 
Table 2 - Health conditions, anthropometric data, and functioning characteristics of 5,783 older adults from the SABE and ELSA studies stratified by sex and mobility status.

\begin{tabular}{|c|c|c|c|c|}
\hline & \multicolumn{2}{|c|}{ Men } & \multicolumn{2}{|c|}{ Women } \\
\hline & Normal mobility & Mobility limitation & Normal mobility & Mobility limitation \\
\hline \multicolumn{5}{|l|}{ Health conditions } \\
\hline Stroke (yes) (\%) & $2.9 *$ & $9.8 * \S$ & $2.3^{*}$ & $7.0 * \S$ \\
\hline Cancer (yes) (\%) & $5.9^{*}$ & $10.2 * \S$ & $4.8^{*}$ & $6.5^{*} \S$ \\
\hline Heart disease (yes) (\%) & $18.3^{*} \S$ & $32.6 * \S$ & $14.0 * \S$ & $27.1 * \S$ \\
\hline Diabetes (yes) (\%) & $12.0 * \S$ & $21.7 *$ & $8.7 * \S$ & $19.3 *$ \\
\hline Joint disease (yes) (\%) & $27.8 * \S$ & $43.2 * \S$ & $41.1 * \S$ & $58.6 * \S$ \\
\hline Arterial hypertension (yes) (\%) & $41.1 *$ & $57.5^{*}$ & $39.4 *$ & $60.3^{*}$ \\
\hline Osteoporosis (yes) (\%) & $1.7 * \S$ & $5.7 * \S$ & $13.0 * \S$ & $24.1 * \S$ \\
\hline Lung disease (yes) (\%) & $11.0 *$ & $17.2 *$ & $12.4^{*}$ & $16.8 *$ \\
\hline Polypharmacy (yes) (\%) & $24.4 *$ & $51.9 *$ & $23.3 *$ & $51.8 *$ \\
\hline Fall in previous 12 months (yes) $(\%)$ & $20.8 * \S$ & $31.5^{*}$ & $25.7 * \S$ & $35.4^{*}$ \\
\hline Depressive symptoms (yes) (\%) & $5.2 * \S$ & $13.8 * \S$ & $10.8 * \S$ & $23.6 * \S$ \\
\hline \multicolumn{5}{|l|}{ Anthropometric characteristics } \\
\hline Grip strength (kg) (SD) & $39.0(8.5)^{* \S}$ & $31.9(9.1)^{* \S}$ & $23.9(5.6)^{* \S}$ & $19.5(6.2)^{* \S}$ \\
\hline Body mass index $\left(\mathrm{kg} / \mathrm{m}^{2}\right)$ & $27.8(4.1)^{*}$ & $28.5(4.6)^{*}$ & $27.7(5.1)^{*}$ & $29.5(6.1)^{*}$ \\
\hline Normal weight $(\%)$ & $24.0 * \S$ & $21.4 * \$$ & $31.2 * \S$ & $22.4 * \S$ \\
\hline Undernourished (\%) & $0.4 * \S$ & $0.7 * \S$ & $1.0 * \S$ & $1.6^{* \S}$ \\
\hline Overweight $(\%)$ & $51.7 * \S$ & $45.9 * \S$ & $39.5 * \S$ & $33.2 * \S$ \\
\hline Obese $(\%)$ & $23.9 * \S$ & $32.0 * \S$ & $28.3 * \S$ & $42.8 * \S$ \\
\hline \multicolumn{5}{|l|}{ Functioning } \\
\hline ADL (mean number of affected activities) (SD) & $0.1(0.4)^{*}$ & $0.5(1.0) * \S$ & $0.1(0.4)^{*}$ & $0.6(1.2)^{* \S}$ \\
\hline IADL (mean number of affected activities) (SD) & $0.0(0.3)^{*}$ & $0.3(0.8) * \S$ & $0.0(0.2)^{*}$ & $0.4(0.8) * \S$ \\
\hline
\end{tabular}

Note: Data expressed as proportion, mean, and standard deviation. ADL - basic activities of daily living; IADL - instrumental activities of daily living; * Difference per mobility status in same sex $(\mathrm{p}<0.05)$. § Difference between sexes within same mobility status $(\mathrm{p}<0.05)$. 
Table 3. Diagnostic properties of handgrip strength cutoffs suggested in present study for identifying mobility limitation and cutoffs reported in literature when applied to present sample

\begin{tabular}{|c|c|c|c|c|c|c|}
\hline \multirow{2}{*}{ Cut-offs } & Sensitivity & Specificity & LR+ & LR- & Youden & $\begin{array}{c}\text { Correct } \\
\text { Classification }\end{array}$ \\
\hline & \multicolumn{6}{|c|}{ Men } \\
\hline$<26 \mathrm{~kg}$ & 26.8 & 94.4 & 4.82 & 0.77 & 21.2 & 74.9 \\
\hline$<27 \mathrm{~kg}$ & 29.5 & 92.9 & 4.15 & 0.76 & 22.4 & 74.6 \\
\hline$<28 \mathrm{~kg}$ & 33.4 & 91.3 & 3.84 & 0.73 & 24.7 & 74.6 \\
\hline$<29 \mathrm{~kg}$ & 36.4 & 89.3 & 3.40 & 0.71 & 25.7 & 74.0 \\
\hline$<30 \mathrm{~kg}$ & 40.4 & 87.1 & 3.12 & 0.68 & 27.5 & 73.6 \\
\hline$<31 \mathrm{~kg}$ & 44.1 & 82.5 & 2.52 & 0.68 & 26.6 & 71.4 \\
\hline \multirow[t]{2}{*}{$<32 \mathrm{~kg}$} & 49.1 & 79.8 & 2.43 & 0.64 & 28.9 & 71.0 \\
\hline & \multicolumn{6}{|c|}{ Women } \\
\hline$<16 \mathrm{~kg}$ & 28.6 & 93.4 & 4.34 & 0.76 & 22.0 & 69.2 \\
\hline$<17 \mathrm{~kg}$ & 33.6 & 90.9 & 3.68 & 0.73 & 24.5 & 69.5 \\
\hline$<18 \mathrm{~kg}$ & 38.1 & 88.3 & 3.24 & 0.70 & 26.4 & 69.5 \\
\hline
\end{tabular}




\begin{tabular}{|c|c|c|c|c|c|c|c|c|}
\hline \multirow{4}{*}{$\begin{array}{l}\text { Note: LR+: positive } \\
\text { negative }\end{array}$} & $<19 \mathrm{~kg}$ & 45.3 & 84.1 & 2.85 & 0.65 & 29.4 & 69.6 & \multirow{4}{*}{$\begin{array}{l}\text { Log-likelihood; } \\
\text { likelihood }\end{array}$} \\
\hline & $<20 \mathrm{~kg}$ & 50.2 & 80.8 & 2.61 & 0.62 & 31.0 & 68.3 & \\
\hline & $<21 \mathrm{~kg}$ & 58.6 & 72.9 & 2.16 & 0.57 & 31.5 & 67.5 & \\
\hline & $<22 \mathrm{~kg}$ & 63.9 & 67.3 & 1.95 & 0.54 & 31.2 & 66.0 & \\
\hline
\end{tabular}


Table 4. Final model for chance of mobility limitation among older men and women according to cutoffs determined in present study and those described in literature applied to present sample.

\begin{tabular}{|c|c|c|c|c|c|c|c|}
\hline & \multicolumn{7}{|c|}{ Men } \\
\hline & $<26 \mathrm{~kg}$ & $<27 \mathrm{~kg}$ & $<28 \mathrm{~kg}$ & $<27 \mathrm{~kg}$ & $<30 \mathrm{~kg}$ & $<31 \mathrm{~kg}$ & $<32 \mathrm{~kg}$ \\
\hline $\mathbf{O R}$ & 3.18 & 2.71 & 2.62 & 2.35 & 2.27 & 1.80 & 1.88 \\
\hline \multirow{4}{*}{$95 \% \mathrm{CI}$} & {$[2.32-$} & {$[2.02-$} & \multirow{2}{*}[1.99-3.46]{} & {$[1.80-$} & \multirow[t]{2}{*}[1.76-2.92]{} & {$[1.42-$} & {$[1.50-$} \\
\hline & $4.35]$ & $3.63]$ & & $3.06]$ & & 2.29] & $2.37]$ \\
\hline & \multicolumn{7}{|c|}{ Women } \\
\hline & $<16 \mathrm{~kg}$ & $<17 \mathrm{~kg}$ & $<18 \mathrm{~kg}$ & $<19 \mathrm{~kg}$ & $<20 \mathrm{~kg}$ & $<21 \mathrm{~kg}$ & $<22 \mathrm{~kg}$ \\
\hline $\mathbf{O R}$ & 2.51 & 2.24 & 2.11 & 2.07 & 2.02 & 1.89 & 1.78 \\
\hline \multirow[b]{2}{*}{$95 \% \mathrm{CI}$} & {$[1.94-$} & {$[1.78-$} & {$[1.70-2.62]$} & {$[1.69-$} & \multirow{2}{*}{\multicolumn{2}{|c|}{$[1.67-2.45] 1.57-2.27]$}} & {$[1.49-$} \\
\hline & $3.25]$ & $2.83]$ & & $2.53]$ & & & 2.13] \\
\hline
\end{tabular}

Note: OR: odds ratio; CI: confidence interval

Figure 1. ROC curve of adjusted model for cut-offs of

$<32 \mathrm{~kg}$ for men and $<21 \mathrm{~kg}$ for women, relation between sensitivity and specificity, and probability of grip strength to identify of mobility limitation among older men (A) and women (B). 
26

A
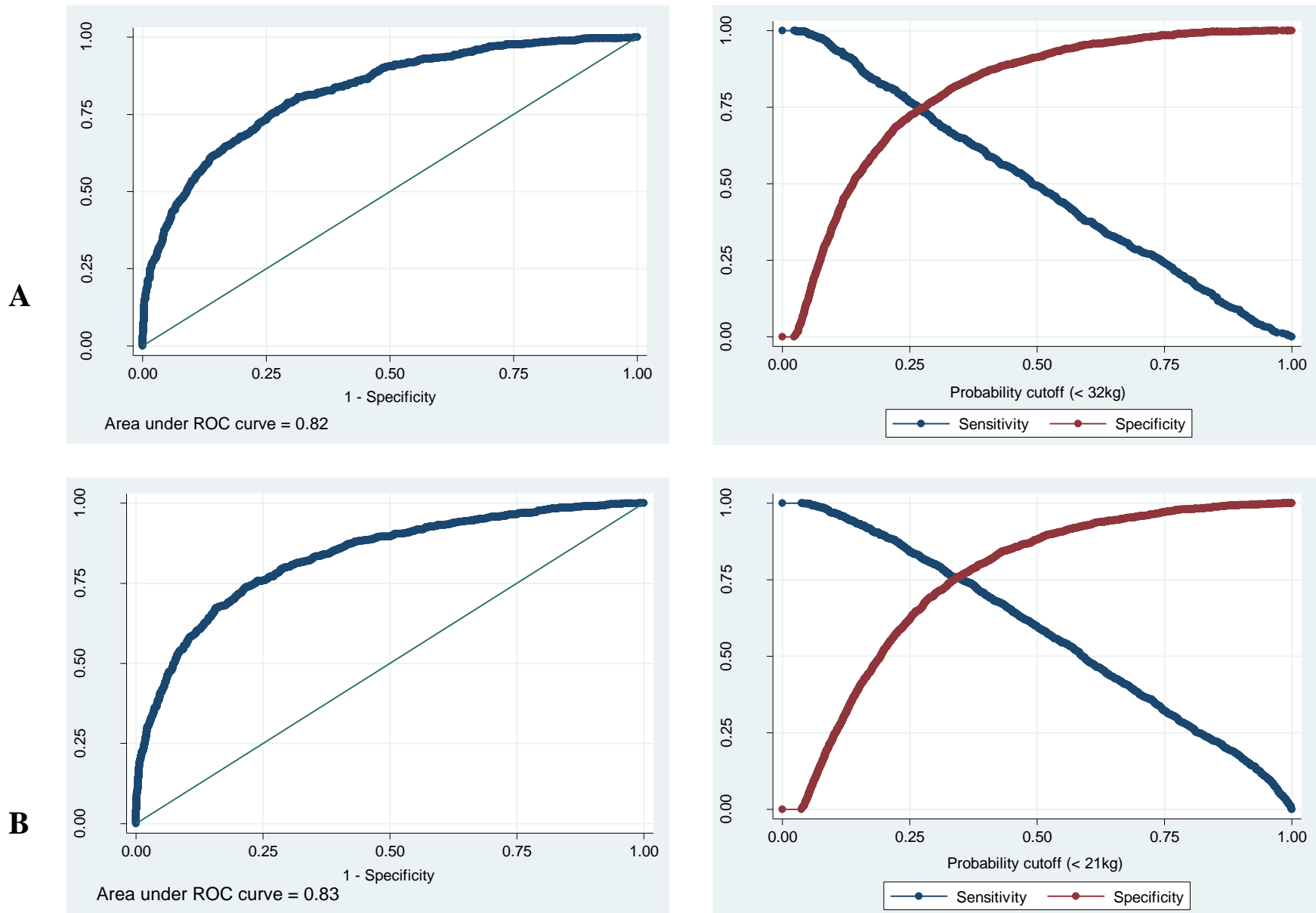